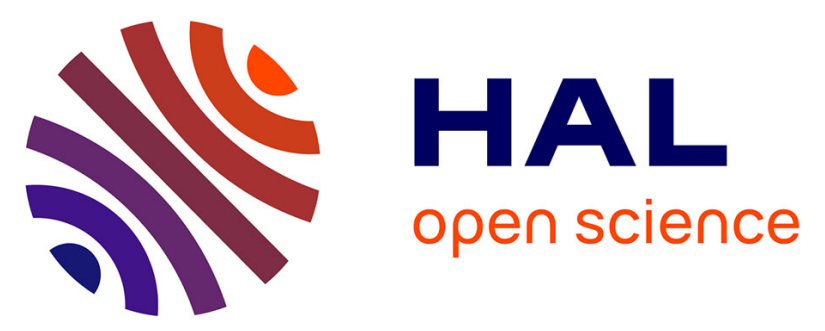

\title{
Association between 25-hydroxyvitamin D levels and cognitive performance in middle-aged and older European men
}

\author{
David M Lee, Abdelouahid Tajar, Aslan Ulubaev, Neil Pendleton, Terence W \\ O’neill, Daryl B O'connor, Gyorgy Bartfai, Steven Boonen, Roger Bouillon, \\ Felipe F Casanueva, et al.
}

\section{To cite this version:}

David M Lee, Abdelouahid Tajar, Aslan Ulubaev, Neil Pendleton, Terence W O'neill, et al.. Association between 25-hydroxyvitamin D levels and cognitive performance in middle-aged and older European men. Journal of Neurology, Neurosurgery and Psychiatry, 2009, 80 (7), pp.722. 10.1136/jnnp.2008.165720 . hal-00552736

\section{HAL Id: hal-00552736 https://hal.science/hal-00552736}

Submitted on 6 Jan 2011

HAL is a multi-disciplinary open access archive for the deposit and dissemination of scientific research documents, whether they are published or not. The documents may come from teaching and research institutions in France or abroad, or from public or private research centers.
L'archive ouverte pluridisciplinaire HAL, est destinée au dépôt et à la diffusion de documents scientifiques de niveau recherche, publiés ou non, émanant des établissements d'enseignement et de recherche français ou étrangers, des laboratoires publics ou privés. 


\section{ASSOCIATION BETWEEN 25-HYDROXYVITAMIN D LEVELS AND COGNITIVE PERFORMANCE IN MIDDLE-AGED AND OLDER EUROPEAN MEN}

David M. Lee ${ }^{1}$, Abdelouahid Tajar ${ }^{1}$, Aslan Ulubaev ${ }^{2}$, Neil Pendleton ${ }^{3}$, Terence W. O’Neill

${ }^{1}$, Daryl B. O'Connor ${ }^{4}$, Gyorgy Bartfai ${ }^{5}$, Steven Boonen ${ }^{6}$, Roger Bouillon ${ }^{7}$, Felipe F. Casanueva ${ }^{8}$, Joseph D. Finn ${ }^{1}$, Gianni Forti ${ }^{9}$, Aleksander Giwercman ${ }^{10}$, Thang S. Han ${ }^{11}$, Ilpo T Huhtaniemi ${ }^{12}$, Krzysztof Kula ${ }^{13}$, Michael E. J. Lean ${ }^{14}$, Margus Punab ${ }^{15}$, Alan J.

Silman ${ }^{1}$, Dirk Vanderschueren ${ }^{16}$, Frederick C. W. Wu ${ }^{2}$, and the EMAS study group*.

${ }^{1}$ ARC Epidemiology Unit, The University of Manchester, Manchester, UK

${ }^{2}$ Department of Endocrinology, Manchester Royal Infirmary, The University of Manchester, Manchester, UK

${ }^{3}$ Clinical Gerontology, The University of Manchester, Hope Hospital, Salford, UK

${ }^{4}$ Institute of Psychological Sciences, University of Leeds, Leeds, UK

${ }^{5}$ Department of Obstetrics, Gynaecology and Andrology, Albert Szent-Gyorgy Medical

University, Szeged, Hungary

${ }^{6}$ Division of Gerontology and Geriatrics \& Centre for Musculoskeletal Research, Department of Experimental Medicine, Katholieke Universiteit Leuven, Leuven, Belgium

${ }^{7}$ Department of Experimental Medicine, Katholieke Universiteit Leuven, Leuven, Belgium

${ }^{8}$ Department of Medicine, Santiago de Compostela University, Complejo Hospitalario

Universitario de Santiago (CHUS); CIBER de Fisiopatología Obesidad y Nutricion

(CB06/03), Instituto Salud Carlos III; Santiago de Compostela, Spain

${ }^{9}$ Andrology Unit, Department of Clinical Physiopathology, University of Florence, Florence, Italy

${ }^{10}$ Reproductive Medicine Centre, Malmö University Hospital, University of Lund, Sweden 
${ }^{11}$ Department of Endocrinology, Royal Free and University College Hospital Medical School, Royal Free Hospital, Hampstead, London, UK

${ }^{12}$ Department of Reproductive Biology, Imperial College London, Hammersmith Campus, London, UK

${ }^{13}$ Department of Andrology and Reproductive Endocrinology, Medical University of Lodz, Lodz, Poland

${ }^{14}$ Department of Human Nutrition, University of Glasgow, Glasgow, Scotland

${ }^{15}$ Andrology Unit, United Laboratories of Tartu University Clinics, Tartu, Estonia

${ }^{16}$ Department of Andrology and Endocrinology, Katholieke Universiteit Leuven, Leuven, Belgium

Corresponding Author: David M. Lee, ARC Epidemiology Unit, The University of Manchester, Manchester, M13 9PT, UK.

Email: david.m.lee@manchester.ac.uk $\quad$ Tel: 00441612757380

Short title: 'Vitamin D and cognitive function in men'

Key words: vitamin D; cognition; ageing; male health; population survey

*The EMAS Study Group: Florence (Gianni Forti, Luisa Petrone, Antonio Cilotti); Leuven (Dirk Vanderschueren, Steven Boonen, Herman Borghs); Lodz (Krzysztof Kula, Jolanta Slowikowska-Hilczer, Renata Walczak-Jedrzejowska); London (Ilpo Huhtaniemi); Malmö (Aleksander Giwercman); Manchester (Frederick Wu, Alan Silman, Neil Pendleton, Terence O’Neill, Joseph Finn, Philip Steer, Abdelouahid Tajar, David Lee, Stephen Pye); Santiago (Felipe Casanueva, Mary Lage); Szeged (Gyorgy Bartfai, Imre Földesi, Imre Fejes); Tartu (Margus Punab, Paul Korrovitz); Turku (Min Jiang) 
1 BACKGROUND: Although there is evidence that vitamin D inadequacy may be linked to

2 adverse cognitive outcomes, results have been inconsistent. The aim of our study was to

3 examine the association between 25-hydroxyvitamin $\mathrm{D}(25(\mathrm{OH}) \mathrm{D})$ levels and cognitive

4 performance in middle-aged and older European men.

5 METHODS: This population-based cross-sectional study included 3,369 men aged 40 to 79

6 years from eight centres enrolled in the European Male Ageing Study (EMAS). Cognitive

7 function was assessed using the Rey-Osterrieth Complex Figure test (ROCF), the Camden

8 Topographical Recognition Memory test (CTRM) and the Digit Symbol Substitution test

9 (DSST). Serum 25(OH)D levels were measured by radioimmunoassay. Additional

10 assessments included physical activity, functional performance and mood/depression.

11 Associations between cognitive function and $25(\mathrm{OH}) \mathrm{D}$ were explored using locally weighted

12 and linear regression models.

13 RESULTS: 3,133 men, mean $( \pm$ SD) age $60 \pm 11$ years were included in the analysis. The

14 mean $25(\mathrm{OH}) \mathrm{D}$ concentration was $63 \pm 31 \mathrm{nmol} / \mathrm{L}$. In age-adjusted linear regressions higher

15 levels of 25(OH)D were associated with higher scores on the ROCF-copy ( $\beta$ per 10

$16 \mathrm{nmol} / \mathrm{L}=0.096 ; 95 \% \mathrm{CI} 0.049-0.144), \mathrm{CTRM}(\beta$ per $10 \mathrm{nmol} / \mathrm{L}=0.075 ; 95 \% \mathrm{CI} 0.026-0.124)$

17 and DSST ( $\beta$ per $10 \mathrm{nmol} / \mathrm{L}=0.318$; 95\%CI 0.235-0.401) tests. After adjusting for additional

18 confounders, 25(OH)D levels were associated with the DSST test only ( $\beta$ per 10

$19 \mathrm{nmol} / \mathrm{L}=0.152 ; 95 \% \mathrm{CI} 0.051-0.253)$. Locally weighted and spline regressions suggested the

20 relationship between $25(\mathrm{OH}) \mathrm{D}$ and cognitive function was most pronounced at $25(\mathrm{OH}) \mathrm{D}$

21 concentrations below $35 \mathrm{nmol} / \mathrm{L}$.

22 CONCLUSION: In this study lower 25(OH)D levels were associated with poorer

23 performance on the DSST test. Further research is warranted to determine whether vitamin D

24 sufficiency may play a role in preserving cognitive function in older adults. 


\section{INTRODUCTION}

27 The essential role of vitamin D on bone health and calcium metabolism has long been

28 recognized ${ }^{1}$. However, a growing body of research has revealed that the vitamin D

29 endocrine system is associated with a broad range of physiological outcomes besides

30 systemic calcium homeostasis ${ }^{2}$. While there are some data to suggest that vitamin D

31 deficiency may have adverse effects on cognition or behaviour ${ }^{3,4}$, there is currently

32 insufficient evidence to draw definitive conclusions. Disagreement remains as to what actual

33 threshold levels of $25(\mathrm{OH}) \mathrm{D}$ best describe either deficient or sub-optimal status, although

34 based on currently recommended levels vitamin D 'inadequacy' has been reported to be

35 highly prevalent ${ }^{5}$.

36 Vitamin D is a fat-soluble secosteroid, primarily synthesized in the skin from 7-

37 dehydrocholesterol following solar UV-B exposure and derived to a lesser extent from

38 dietary sources. Vitamin $\mathrm{D}$ is hydroxylated to $25(\mathrm{OH}) \mathrm{D}$ in the liver and subsequently to the

39 main active molecule, 1,25-dihydroxyvitamin $\mathrm{D}\left(1,25(\mathrm{OH})_{2} \mathrm{D}\right)$, principally in the kidneys ${ }^{6}$.

40 Serum 25(OH)D levels are typically measured to establish the vitamin D status of an

41 individual. $1,25(\mathrm{OH})_{2} \mathrm{D}$ exerts its biological effect both via the nuclear vitamin $\mathrm{D}$ receptor

42 (VDR), thereby modulating the expression of numerous target genes, and through binding to

43 cell membrane receptors, initiating rapid non-genomic intracellular signalling ${ }^{3}$. The VDR

44 has been found in key areas of the brain known to regulate behaviour, i.e., the cortex,

45 cerebellum and limbic system, and it is often co-localized in the same cells with $1 \propto$

46 hydroxylase, the final enzyme in the vitamin D activation pathway ${ }^{7}$. In vitro experiments

47 have demonstrated that vitamin D has both neurotrophic and neuroprotective properties ${ }^{8 ; 9}$,

48 whilst long-term $1,25(\mathrm{OH})_{2} \mathrm{D}$ supplementation has been shown to retard hippocampal ageing

49 in rats ${ }^{10}$. Together, such findings suggest that the active form of vitamin D may function as a

50 neuro-steroid. 
51 Although the influence of vitamin D on brain function is biologically plausible there have

52 been few studies exploring the association between vitamin D status and adult cognitive

53 function. Two recent clinic-based observational studies reported that lower serum 25(OH)D

54 levels were associated with poorer cognitive test performance among patients with mild

55 Alzheimer's disease ${ }^{11 ; 12}$, while a retrospective study of older adults attending a memory

56 assessment clinic found a positive correlation between $25(\mathrm{OH}) \mathrm{D}$ levels and scores on the

57 mini-mental state examination ${ }^{13}$. Conversely, a cross-sectional analysis of a sub-sample of

58 participants with secondary hyperparathyroidism from the Troms $\emptyset$ study reported no

59 association between $25(\mathrm{OH}) \mathrm{D}$ levels and a battery of 14 neuropsychological tests. Overall,

60 these studies were not generalizable to community-dwelling individuals and were limited by

61 small sample sizes and failure to adjust for multiple confounders. To the best of our

62 knowledge there has been only one large, community-based study that has examined the

63 association between vitamin D and cognitive function. McGrath et al. ${ }^{14}$ utilised NHANES

64 III survey data and found no evidence of an association between lower 25(OH)D levels and

65 impaired neurocognitive performance. However, this study failed to adjust for potential

66 confounders, such as education and depression, and used different cognitive tests for different

67 age groups.

68 We used baseline data from the European Male Ageing Study (EMAS), a large population-

69 based study of ageing in middle-aged and older men, to evaluate the association between

70 vitamin D levels and cognition. In addition to standardised measurements of cognitive

71 function, EMAS includes comprehensive lifestyle and functional assessments. This allowed

72 us to adjust our analyses for a wide range of possible confounders of the association between

73 vitamin D and cognition. 


\section{METHODS}

\section{Subjects}

78 The major aims of EMAS are to examine the nature, prevalence and incidence of symptoms 79 associated with physiological ageing, exploring their relationships with endocrine functions 80 and other predisposing risk variables. There are two phases: a cross-sectional survey of a 81 random population sample of middle-aged and older men which was completed in 2005 and a

82 follow-up assessment which is scheduled for completion in 2009. Details regarding 83 recruitment, response rates and assessments in EMAS have been described previously ${ }^{15}$.

84 Briefly, non-institutionalized men aged 40-79 years were recruited from municipal or 85 population registers in eight centres: Florence (Italy); Leuven (Belgium); Lodz (Poland); 86 Malmö (Sweden); Manchester (UK); Santiago de Compostela (Spain); Szeged (Hungary);

87 Tartu (Estonia). For the baseline survey, stratified random sampling was used with the aim 88 of recruiting equal numbers of men into each of four age bands $(40-49,50-59,60-69$ and $70-$

8979 years). Subjects were invited by letter to complete a short postal questionnaire and to 90 attend for screening at a local clinic. The study was funded by the European Union and

91 ethical approval for the study was obtained in accordance with local institutional

92 requirements in each centre.

94 Assessments

95 The short postal questionnaire included items concerning demographic, health and lifestyle 96 information. Subjects were asked about tobacco use (response set = current / past / non97 smoker), typical alcohol consumption during the preceding month (response set = every day /

98 5-6 days/week / 3-4 days/week / 1-2 days/week / < once/week / not at all), and the age they

99 left full-time education. Those who agreed to participate subsequently attended a research 100 clinic to complete an interviewer-assisted questionnaire (IAQ) and assessment of cognitive 
function (see below). The IAQ included the Physical Activity Scale for the Elderly (PASE) ${ }^{16}$ and the 21-item Beck Depression Inventory (BDI) to assess the presence and severity of depressive symptoms ${ }^{17}$. In addition, physical function was assessed during the clinic visit using Reuben's Physical Performance test $(\mathrm{PPT}){ }^{18}$. Height and weight were measured using standardized instruments.

\section{Serum 25-hydroxyvitamin D}

Morning phlebotomy was performed prior to 10 a.m. to obtain a fasting blood sample from all subjects. Processed serum was stored at $-80^{\circ} \mathrm{C}$ prior to analysis and shipped on dry-ice to a single laboratory (University of Leuven) for measurement of 25(OH)D. Serum 25(OH)D levels were determined using a radioimmunoassay (RIA kit: DiaSorin, Stillwater, MN, USA). Intra- and inter-assay coefficients of variation for $25(\mathrm{OH}) \mathrm{D}$ were $11 \%$ and $9 \%$, respectively. The detection limit of the RIA kit was $3.7 \mathrm{nmol} / \mathrm{L} 25(\mathrm{OH}) \mathrm{D}$.

\section{Tests of cognitive function}

To assess cognitive function subjects were asked to complete a battery of three neuropsychological tests; the Rey-Osterrieth Complex Figure (ROCF), the Camden Topographical Recognition Memory (CTRM) and the Digit-Symbol Substitution (DSST) test. These tests assess the domains of visuo-constructional ability, memory, recognition, and speed of information processing, and were selected on the basis that they could be standardized across centres independent of culture and language.

Copying and delayed reproduction of the ROCF was used as a measure of visual perceptual abilities and visual memory ${ }^{19}$. The scoring criteria used was based upon Osterreith's original test procedure which defined 18 units of the drawing, assigning point values of 0 to 2 to each unit dependent upon the degree to which the units are correctly drawn and placed. Each 
element of the ROCF test had a maximum score of 36. The CTRM, developed in order to measure the recognition component of visual memory retrieval, taps into the cortical component of visual memory ${ }^{20}$. The CTRM involves the presentation of 30 coloured photographs of outdoor topographical scenes, each for 3 seconds, followed by a three-way forced recognition component. The CTRM had a maximum score of 30 . The DSST is a subtest adopted from the Wechsler Adult Intelligence Scales and provides a reliable measure of psychomotor speed and visual scanning ${ }^{21}$. Subjects were asked to make as many correct symbol-for-digit substitutions as possible within a 1 minute period.

\section{Analysis}

Analyses were undertaken using the statistical package Intercooled STATA version 9.2 (StataCorp, College Station, TX, USA). Subjects with missing cognitive and/or 25(OH)D data were excluded from the analysis. Age (years), age leaving education, and BMI $\left(\mathrm{kg} / \mathrm{m}^{2}\right)$ were analyzed as continuous variables. The BDI score was treated both as a continuous and categorical variable, with the latter based upon Beck's original cut-off scores ${ }^{17}$. Both the PASE and PPT scores were treated as continuous variables and also categorized into tertiles. $25(\mathrm{OH}) \mathrm{D}$ was examined as a continuous variable and classified into sub-optimal (50-75 $\mathrm{nmol} / \mathrm{L})$, insufficiency $(25-49 \mathrm{nmol} / \mathrm{L})$ and deficiency $(<25 \mathrm{nmol} / \mathrm{L})$ groups broadly based on previously recommended cut-points ${ }^{22 ; 23}$.

The relationship between $25(\mathrm{OH}) \mathrm{D}$ levels and cognitive function was initially evaluated graphically (while simultaneously adjusting for age) using the LOcally WEighted Scatterplot Smoothing (LOWESS) technique ${ }^{24}$. This approach, where linear regression is applied repeatedly to sequential small sections of the covariate-outcome relationship, is primarily exploratory. By reducing the influence of outliers, this technique provides a smooth fit to the data so that relationships and thresholds can be more readily identified. The associations 
151 between cognitive test scores and factors that could potentially confound the relationship

152 between cognitive function and $25(\mathrm{OH}) \mathrm{D}$ were explored using linear regression, with

153 adjustments made for age. Multiple linear regression models were then used to examine the

154 association between $25(\mathrm{OH}) \mathrm{D}$ levels and cognitive function, with the cognitive test scores as

155 dependent variables. Adjustments were made for factors that showed a significant

156 association $(P<0.05)$ with $25(\mathrm{OH}) \mathrm{D}$ status and cognitive function in age-adjusted models.

157 Regression models were additionally adjusted for centre and season of the year (winter [Jan-

158 March], spring [April-June], summer [July-Sept], autumn [Oct-Dec]), to account for seasonal

159 effects on 25(OH)D. Effect modification by age was also assessed by inclusion of interaction

160 terms between $25(\mathrm{OH}) \mathrm{D}$ and age (by decade) in the regression models.

161 To further explore the relationship between cognitive function and 25(OH)D we used a

162 spline or piecewise regression approach whereby the model fits linear segments to different

163 ranges of the data. Breakpoints, the level of $25(\mathrm{OH}) \mathrm{D}$ where the slope of the linear function

164 changes, were estimated from the LOWESS plots. The mkspline function within STATA

165 allows the regression function to be continuous at all points including the breakpoint. All

166 regression results are expressed as $\beta$ coefficients and 95\% confidence intervals (CI). 


\section{RESULTS}

A total of 138 subjects with missing vitamin D data (16 missing blood samples, 122 assay failures) and 98 subjects with incomplete cognitive data were excluded from this analysis. The baseline characteristics of the remaining 3,133 men are shown in Table 1.

The results from the LOWESS analyses exploring the association between $25(\mathrm{OH}) \mathrm{D}$ and cognitive performance (while adjusting for age) are shown in Figure 1. Only the LOWESS plot of 25(OH)D versus the DSST score was suggestive of an overall positive association (Figure 1D). However, at 25(OH)D levels of approximately $35 \mathrm{nmol} / \mathrm{L}$ and under, a more pronounced positive relationship between $25(\mathrm{OH}) \mathrm{D}$ and all four cognitive test scores was apparent.

Table 2 summarizes the influence of factors which could potentially confound the relationship between $25(\mathrm{OH}) \mathrm{D}$ levels and cognitive function. There were significant crosssectional age-related decreases in all four cognitive test scores, but there was no association between 25(OH)D and age $(\beta=-0.0135 ; 95 \%$ CI $-0.114,0.087)$. Depression (BDI), BMI, physical activity (PASE), physical performance (PPT) and smoking were all consistently associated with both cognitive test scores and 25(OH)D. The CTRM and DSST scores, together with 25(OH)D levels, were additionally associated with drinking one or more alcoholic drink per week. As expected, 25(OH)D levels varied markedly by season of measurement peaking in the summer (mean $85.0 \mathrm{nmol} / \mathrm{L}$ ) with a nadir in the winter (mean $49.7 \mathrm{nmol} / \mathrm{L})$. Mean serum 25(OH)D also varied by significantly by geographical region (one-way ANOVA, $P<0.001$ ), with highest levels observed in northern and western European centres $(72.6 \mathrm{nmol} / \mathrm{L})$, lower levels in southern centres $(60.5 \mathrm{nmol} / \mathrm{L})$, and the lowest levels in eastern European centres (53.9 nmol/L).

The results from the regression models exploring the association between $25(\mathrm{OH}) \mathrm{D}$ and cognition are summarized in Table 3. In age adjusted linear regressions increasing $25(\mathrm{OH}) \mathrm{D}$ 
levels were associated with higher scores in the ROCF copy test $(\beta$ per $10 \mathrm{nmol} / \mathrm{L}=0.096$; 95\% CI $0.049,0.144)$, the CTRM test $(\beta$ per $10 \mathrm{nmol} / \mathrm{L}=0.075 ; 95 \% \mathrm{CI} 0.026,0.124)$, and the DSST test $(\beta$ per $10 \mathrm{nmol} / \mathrm{L}=0.318 ; 95 \%$ CI 0.235, 0.401). However, after additional adjustments for age left education, depression, BMI, physical activity, physical performance, smoking, alcohol consumption, season and centre, increasing $25(\mathrm{OH}) \mathrm{D}$ was found to be only associated with higher DSST scores $(\beta$ per $10 \mathrm{nmol} / \mathrm{L}=0.152 ; 95 \% \mathrm{CI} 0.051,0.253)$. No association was observed between $25(\mathrm{OH}) \mathrm{D}$ and the ROCF copy, ROCF recall, and CTRM scores in fully adjusted models. The association between increasing 25(OH)D levels and higher DSST scores was also observed when 25(OH)D was classified into sub-optimal (50$74.9 \mathrm{nmol} / \mathrm{L})$, insufficiency ( $25-49 \mathrm{nmol} / \mathrm{L})$ and deficiency (<25 nmol/L) groups. When subjects who reported taking any form of vitamin D/calcium supplements were excluded from the regression analyses the results remained the same (data not shown). Excluding the season and centre covariates from the regression analyses did not significantly affect the results (DSST test: $\beta$ per $10 \mathrm{nmol} / \mathrm{L}=0.126 ; 95 \%$ CI $0.043,0.209)$. Although the $\mathrm{ROCF}$ copy data was left skewed, linear regression performs well in moderately large samples (n > $500)$ even from very non-Normal data ${ }^{25}$. However, to verify the results of the linear regression models we inverted the ROCF copy score and considered it as count data. The transformed data followed a negative binomial distribution (variance larger than the mean, data over-dispersed). We then carried out a negative binomial regression analysis using the same covariates as in the linear model and found the same result, i.e., no evidence of an independent association between the ROCF copy score and 25(OH)D (data not shown). Additional regression models demonstrated a significant age by $25(\mathrm{OH}) \mathrm{D}$ interaction effect with DSST as the outcome $\left(P_{\text {interaction }}=0.01\right)$. In fully adjusted linear regressions stratified by age decade, with $25(\mathrm{OH}) \mathrm{D}$ as a continuous variable, higher DSST scores were found to be associated with $25(\mathrm{OH}) \mathrm{D}$ only among older men (DSST test: $\beta$ per $10 \mathrm{nmol} / \mathrm{L}=0.258 ; 95 \%$ 
CI 0.1350 .381 [60-69 years]; $\beta$ per $10 \mathrm{nmol} / \mathrm{L}=0.215 ; 95 \%$ CI $0.105,0.326$ [over 70 years])

227

228

229

230

247

248

249

250

\section{4}

and not younger men (DSST test: $\beta$ per $10 \mathrm{nmol} / \mathrm{L}=0.044 ; 95 \% \mathrm{CI}-0.153,0.242[40-49$

years]; $\beta$ per $10 \mathrm{nmol} / \mathrm{L}=0.097 ; 95 \% \mathrm{CI}-0.124,0.317$ [50-59 years]). There were no age by

$25(\mathrm{OH}) \mathrm{D}$ interactions for ROCF copy $\left(P_{\text {interaction }}=0.5\right)$, ROCF recall $\left(P_{\text {interaction }}=0.7\right)$ and

CTRM $\left(P_{\text {interaction }}=0.3\right)$, nor evidence of any significant season by $25(\mathrm{OH}) \mathrm{D}$, centre by

$25(\mathrm{OH}) \mathrm{D}$, or season by physical activity interaction effects for any of the four cognitive outcomes (data not shown).

The LOWESS plots (see Figure 1) suggested that the relationship between 25(OH)D and the four cognitive outcomes may not be best explored by a single linear function and that the slope of the relationships changed at around 30-40 nmol/L 25(OH)D. We used spline regression models, therefore, to better describe the $25(\mathrm{OH}) \mathrm{D}$ - cognitive function relationship (see Table 4). The breakpoint at which the slope of the linear relationship was allowed to change was estimated to be $35 \mathrm{nmol} / \mathrm{L} \mathrm{25(OH)D.} \mathrm{Spline} \mathrm{models} \mathrm{adjusted} \mathrm{only} \mathrm{for} \mathrm{age}$ confirmed that the strength of the association between 25(OH)D and cognitive function (as assessed by the relative magnitude of the $\beta$ coefficients) was greater at $25(\mathrm{OH}) \mathrm{D}$ levels $\leq 35$ nmol/l as compared to higher levels. Although the same pattern was evident in spline models adjusted for age and the other covariates, none of the $\beta$ coefficients reached statistical significance. 


\section{DISCUSSION}

252 In this population-based study of European men aged $\geq 40$ years we observed a significant, 253 independent association between a slower information processing speed (as assessed by the 254 DSST test) and lower levels of 25(OH)D. The association appeared strongest among those 255 with a $25(\mathrm{OH}) \mathrm{D}$ level less than $\sim 35 \mathrm{nmol} / \mathrm{L}$.

256 Previous studies exploring the relationship between vitamin D and cognitive performance in 257 adults have produced inconsistent findings, with only one other large, population-based study 258 having specifically examined the relationship between vitamin D and cognition in 259 community-dwelling individuals. Using data from the NHANES III survey, McGrath et. al. $260{ }^{14}$ concluded that serum $25(\mathrm{OH}) \mathrm{D}$ levels were not associated with neurocognitive 261 performance in adults. One of the neuropsychological tests they used (Symbol Digit 262 Substitution) assesses broadly the same cognitive domain as the DSST, i.e., speed of 263 information processing. However, their study included both men and women, and the age 264 group assessed using the symbol digit substitution test was significantly younger (20-59 years) than our sample. They did observe an association between vitamin D status and

266 learning and memory tasks in their oldest group (60-90 years) ${ }^{14}$, but presented no data on 267 speed of information processing in this group. Interestingly, when we stratified our regression analyses by age decade the association between increased $25(\mathrm{OH}) \mathrm{D}$ and a higher DSST score was only significant among the older men, i.e., 60-69 years and 70-79 years.

270 Although the lack of an association between 25(OH)D and DSST among men under 60 years 271 of age may have been due to insufficient power in the stratified analyses, it is intriguing to 272 speculate that any 'potential' beneficial effect of $25(\mathrm{OH}) \mathrm{D}$ on psychomotor processing speed 273 may be more pronounced in older men.

274 It was notable that the only significant association in fully adjusted regression models was 275 observed between 25(OH)D and the DSST. Although we are unable to specifically explain 
this, the DSST appears robust to ceiling effects, as opposed to the ROCF copy score and to a

lesser extent the CTRM score, and this may in part have enhanced the tests sensitivity at upper levels in our cognitively-intact, generally healthy sample. To further explore potential differential relationships across cognitive domains would require more sensitive and exhaustive neuropsychological test batteries than our study schedule allowed.

Although experimental models in animals and in vitro studies point to the biological plausibility of low $25(\mathrm{OH}) \mathrm{D}$ levels resulting in impaired cognitive performance, the mechanisms by which vitamin D affects adult cerebral functions remain unknown. Possible positive effects could be direct, as suggested by the observation that $1,25(\mathrm{OH})_{2} \mathrm{D}$ treatment increases choline acetyltransferase activity in rat brain nuclei ${ }^{26}$, or they could operate via a neuroprotective pathway, as demonstrated by the stimulation of neurotrophin production ${ }^{27}$ and modulation of neuronal $\mathrm{Ca}^{2+}$ homeostasis ${ }^{9}$ by vitamin D. It is also plausible that additional factors not included in this analysis, such as parathyroid hormone (PTH) and calcium levels, may be involved in a more complex relationship with cognitive function. Evidence for such a relationship comes from the Troms $\emptyset$ health study, where a subset of subjects with secondary hyperparathyroidism were found to perform less well than normal controls on cognitive tests assessing working memory capacity and speed of information processing ${ }^{28}$. Although their data derives from individuals with an overt endocrine disorder, the Troms $\emptyset$ investigators found no evidence of any independent associations between 25(OH)D and cognitive performance. They did observe, however, that low serum 25(OH)D was significantly associated with a higher depression score. The relationship between vitamin $\mathrm{D}$ and mood/depression has yet to be substantiated ${ }^{3}$, although we did find an inverse association between 25(OH)D levels and the BDI score (see Table 2).

In the context of the cross-sectional nature of the data presented here, any association between $25(\mathrm{OH}) \mathrm{D}$ and cognitive function can be interpreted in a number of ways. It is 
possible that low serum $25(\mathrm{OH}) \mathrm{D}$ is merely a 'risk marker' and mechanistically separated from the biological processes resulting in declining cognitive performance in older adults. Low levels of $25(\mathrm{OH}) \mathrm{D}$ have been shown to be associated with a number of unfavourable health outcomes including, cardiovascular disease ${ }^{29}$, increased cancer risk and mortality ${ }^{30}$, sarcopenia ${ }^{31}$, and diabetes ${ }^{32}$. Several population-based studies have documented the relationship between cardiovascular and metabolic diseases and cognitive impairment ${ }^{33-35}$. When we additionally adjusted for self-reported cardiovascular disease and diabetes in our regression models the associations between $25(\mathrm{OH}) \mathrm{D}$ and DSST remained unchanged (data not shown). Conversely, cognitive impairment itself may contribute to lower levels of $25(\mathrm{OH}) \mathrm{D}$ by reducing the level of outdoor physical activity and hence exposure to sunlight. Interestingly, there is increasing evidence supporting the association between vitamin D deficiency and decreased physical performance ${ }^{36}$, though cause and effect has yet to be differentiated. This raises the possibility that the positive association between $25(\mathrm{OH}) \mathrm{D}$ and psychomotor processing speed seen in our study may, in part, reflect improved physical motor speed. In an attempt to better control for this confounder in our data, we included only the score from the seven timed elements from the PPT (in place of the total score) in our regression models. However, the relationship between $25(\mathrm{OH}) \mathrm{D}$ and the DSST score remained unchanged, suggesting that the association may be more to do with neuronal processing speed than muscle/motor speed. Overall, we attempted to adjust for potential confounders in our analysis but cannot exclude the possibility that some of our findings may be due to unmeasured factors and/or residual confounding.

There remains uncertainty as to what level of vitamin D indicates a sub-optimal or deficient status. There is strong evidence that $25(\mathrm{OH}) \mathrm{D}$ levels below $12.5 \mathrm{nmol} / \mathrm{L}$ can result in bone diseases such as rickets in infants and osteomalacia in adults ${ }^{37}$, although to the best of our knowledge no previous studies have assessed cognitive function in subjects with such overt 
hypovitaminosis D. Serum $25(\mathrm{OH}) \mathrm{D}$ concentrations above $50 \mathrm{nmol} / \mathrm{L}$ are generally defined as sufficient, although recent studies have suggested that serum $25(\mathrm{OH}) \mathrm{D}$ levels below 75 $\mathrm{nmol} / \mathrm{L}$ are sub-optimal for health ${ }^{38 ; 39}$. Nonetheless, our data showing that $8 \%$ of subjects have 25(OH)D levels below $25 \mathrm{nmol} / \mathrm{L}$ (deficiency) and $33 \%$ have levels between 25 and 50 $\mathrm{nmol} / \mathrm{L}$ (insufficiency), broadly agrees with previous reports from Europe ${ }^{5 ; 40}$. In terms of any relationship between a given threshold level of $25(\mathrm{OH}) \mathrm{D}$ and reduced cognitive performance, our data suggest that cognitive function is increasingly negatively associated with $25(\mathrm{OH}) \mathrm{D}$ at levels below around $35 \mathrm{nmol} / \mathrm{L}$. However, in spline regression models adjusted for age and other covariates (see Table 4) none of the associations between 25(OH)D (either above or below $35 \mathrm{nmol} / \mathrm{L}$ ) and cognitive function were statistically significant. This may in part be due to insufficient power to detect the relatively modest changes in, for example the DSST score, with varying levels of 25(OH)D.

Although we have referred to $25(\mathrm{OH}) \mathrm{D}$ throughout, vitamin D exists in two common forms; vitamin $\mathrm{D}_{3}$ (cholecalciferol) and vitamin $\mathrm{D}_{2}$ (ergocalciferol). The form mainly produced in the skin and derived from natural dietary sources is vitamin $\mathrm{D}_{3}$, while the primary source of vitamin $\mathrm{D}_{2}$ is multivitamin preparations and some fortified foods ${ }^{41}$. There have been conflicting reports whether vitamin $\mathrm{D}_{2}$ and vitamin $\mathrm{D}_{3}$ are equally effective at maintaining $25(\mathrm{OH}) \mathrm{D}$ levels ${ }^{42 ; 43}$, with another study suggesting that the $\mathrm{D}_{2}$ form may actually have a negative effect on $25(\mathrm{OH}) \mathrm{D}_{3}$ status ${ }^{44}$. The immunoassay used in our study has the same reported sensitivity to both forms of $25(\mathrm{OH}) \mathrm{D}$ (data from manufacturers manual), so the reported $25(\mathrm{OH}) \mathrm{D}$ levels here are the sum of $25(\mathrm{OH}) \mathrm{D}_{2}+25(\mathrm{OH}) \mathrm{D}_{3}$. As we have no information as to the relative abundance of each form within samples, we are unable to draw any conclusions as to the different associations, if any, between $25(\mathrm{OH}) \mathrm{D}_{2}$ or $25(\mathrm{OH}) \mathrm{D}_{3}$ and cognitive performance. Future studies in animals or in vitro may shed more light on whether 
or not the $\mathrm{D}_{2}$ and $\mathrm{D}_{3}$ forms of vitamin $\mathrm{D}$ are differentially associated with brain function and/or development.

The main strengths of our study are that it is based on a large population-based sample and used uniform methods to not only assess vitamin D status, but also potential confounders such as depressed mood, physical activity and physical function. In addition, the battery of cognitive tests was specifically selected on the basis that they could be standardized across different centres and applied to individual subjects independent of language and culture. Methodological limitations inherent to the EMAS study have been described in detail previously ${ }^{15}$, although a number of specific factors need be considered in interpreting the results presented here. The overall response rate for participation in the study was $41 \%$. Those who participated may have differed with respect to levels of cognitive function and also vitamin D status than those who did not participate and some caution, therefore, is needed in interpreting these data. The main findings, however, were based on an internal comparison of responders and therefore any selection factors were unlikely to have had any important effect on these data. Our analysis was restricted to vision-based tests of cognitive function. This was primarily to avoid language and cultural effects inherent in many text based tests, but also due to the practical constraints of a large, population-based study. Although serum 25(OH)D levels remain the accepted metric of vitamin D status, it is questionable whether the single $25(\mathrm{OH}) \mathrm{D}$ measurement performed in our study reflects each subject's long-term vitamin D status. The single 25(OH)D value would be an indicator of sun exposure and dietary intake over the past few weeks, rather than years, thereby increasing random measurement error. The net result of this would be to reduce the reported associations between $25(\mathrm{OH}) \mathrm{D}$ and cognitive function toward the null rather than produce spurious associations. Finally our results were obtained from a predominantly Caucasian European population and should be extrapolated beyond this setting with care. 


\section{CONCLUSION}

377 In this population-based study of middle-aged and older European men lower levels of serum $25(\mathrm{OH}) \mathrm{D}$ were significantly associated with slower psychomotor processing speed as

379 measured by the DSST test. This relationship may be more pronounced among men with $38025(\mathrm{OH}) \mathrm{D}$ levels below $35 \mathrm{nmol} / \mathrm{L}$ and in age-stratified analyses appeared to be restricted to older men. Although the magnitude of the association between $25(\mathrm{OH}) \mathrm{D}$ and processing

speed was comparatively small, if cognitive function can be improved by a simple intervention such as vitamin D supplementation, this would have potentially important implications for population health. In light of our findings, and the fact that vitamin D inadequacy is common among adults, further prospective studies are warranted to determine whether vitamin D supplementation could aid in minimizing ageing-related declines in specific cognitive domains.

\section{ACKNOWLEDGEMENTS}

The European Male Ageing Study is funded by the Commission of the European Communities Fifth Framework Program "Quality of Life and Management of Living Resources” Grant QLK6-CT-2001-00258. Additional support was also provided by the Arthritis Research Campaign. The authors wish to thank the men who participated in the eight countries, the research/nursing staff in the eight centres: C Pott, Manchester, E Wouters, Leuven., M Nilsson, Malmö, M del Mar Fernandez, Santiago de Compostela, M Jedrzejowska, Lodz, H-M Tabo, Tartu, A Heredi, Szeged for their data collection, C Moseley, Manchester for data entry and project co-ordination, and E Van Herck, Leuven for performing the $25(\mathrm{OH}) \mathrm{D}$ assays. 
401 Conflict of Interest: The authors have no financial arrangements or conflict of interest to 402 disclose concerning this manuscript.

403

404 Sponsor's Role: None.

405

406 Licence statement: "The Corresponding Author has the right to grant on behalf of all authors 407 and does grant on behalf of all authors, an exclusive licence (or non exclusive for government 408 employees) on a worldwide basis to the BMJ Publishing Group Ltd and its Licensees, to 409 permit this article (if accepted) to be published in JNNP and any other BMJ Group products

410 and to exploit all subsidiary rights, as set out in our licence

411 (http://jnnp.bmjjournals.com//ifora/licence.pdf)" 


\section{GRAPHICS}

Table 1. Baseline characteristics $(n=3,133)$

\begin{tabular}{|c|c|}
\hline Variable & Mean (SD) \\
\hline Age (years) & $59.9(11.0)$ \\
\hline $25(\mathrm{OH}) \mathrm{D}(\mathrm{nmol} / \mathrm{L})$ & $62.5(31.4)$ \\
\hline Age left education (years) & $20.9(7.7)$ \\
\hline Beck Depression Inventory & $6.8(6.4)$ \\
\hline Body Mass Index (kg/m²) & $27.7(4.1)$ \\
\hline Physical Activity Scale for the Elderly & $197(92)$ \\
\hline Reuben's Physical Performance Test & $23.9(2.7)$ \\
\hline Rey-Osterrieth Complex Figure (copy) & $33.3(4.5)$ \\
\hline Rey-Osterrieth Complex Figure (recall) & $17.0(6.6)$ \\
\hline Camden Topographical Recognition Memory & $22.7(4.7)$ \\
\hline \multirow[t]{2}{*}{ Digit Symbol Substitution Test } & $27.5(8.8)$ \\
\hline & $\%$ \\
\hline \multicolumn{2}{|l|}{ 25(OH)D status: } \\
\hline Sufficient $(\geq 75.0 \mathrm{nmol} / \mathrm{L})$ & 28.8 \\
\hline Sub-optimal (50.0 - $74.9 \mathrm{nmol} / \mathrm{L})$ & 30.5 \\
\hline Insufficiency $(25.0-49.9 \mathrm{nmol} / \mathrm{L})$ & 32.8 \\
\hline Deficiency $(<25.0 \mathrm{nmol} / \mathrm{L})$ & 7.9 \\
\hline \multicolumn{2}{|l|}{ Beck Depression Inventory band (score): } \\
\hline Normal $(0-10)$ & 78.1 \\
\hline Mild - Borderline $(11-20)$ & 18.0 \\
\hline Moderate - Extreme (21+) & 3.9 \\
\hline Current smoker & 20.9 \\
\hline Alcohol consumption ( $\geq 1$ day/week) & 56.7 \\
\hline Vitamin $\mathrm{D} / \mathrm{Ca}^{2+}$ supplementation & 0.7 \\
\hline
\end{tabular}

$\mathrm{SD}=$ standard deviation 
Table 2. Determinants of cognitive test scores and 25(OH)D levels: linear regression analyses

\begin{tabular}{|c|c|c|c|c|c|}
\hline & ROCF copy score & ROCF recall score & CTRM score & DSST score & 25(OH)D (nmol/L) \\
\hline & & & $\beta$ coefficient $(95 \% \mathrm{CI})^{\dagger}$ & & \\
\hline Age (years) & $-0.127(-0.142,-0.113)^{*}$ & $-0.228(-0.247,-0.208)^{*}$ & $-0.163(-0.177,-0.149)^{*}$ & $-0.415(-0.439,-0.391)^{*}$ & $-0.0135(-0.114,0.087)$ \\
\hline Age left education (years) & $0.097(0.077,0.116)^{*}$ & $0.129(0.101,0.157)^{*}$ & $0.060(0.039,0.080)^{*}$ & $0.199(0.165,0.233)^{*}$ & $-0.127(-0.272,0.017)$ \\
\hline BDI score & $-0.044(-0.068,-0.021)^{*}$ & $-0.088(-0.122,-0.055)^{*}$ & $-0.071(-0.095,-0.047)^{*}$ & $-0.177(-0.217,-0.136)^{*}$ & $-0.815(-0.985,-0.644)^{*}$ \\
\hline $\begin{array}{l}\text { BDI category: } \\
\text { Normal }(0-10) \\
\text { Mild - Borderline }(11-20) \\
\text { Moderate - Extreme }(21+)\end{array}$ & $\begin{array}{c}\text { Reference } \\
-0.218(-0.610,0.173) \\
-1.585(-2.361,-0.809) *\end{array}$ & $\begin{array}{c}\text { Reference } \\
-0.732(-1.293,-0.172)^{*} \\
-2.264(-3.375,-1.154)^{*}\end{array}$ & $\begin{array}{c}\text { Reference } \\
-0.849(-1.252,-0.446)^{*} \\
-1.433(-2.231,-0.636)^{*}\end{array}$ & $\begin{array}{c}\text { Reference } \\
-1.743(-2.427,-1.058)^{*} \\
-4.050(-5.405,-2.695) *\end{array}$ & $\begin{array}{c}\text { Reference } \\
-9.641(-12.51,-6.774)^{*} \\
-13.93(-19.61,-8.249)^{*}\end{array}$ \\
\hline Body Mass Index $\left(\mathrm{kg} / \mathrm{m}^{2}\right)$ & $-0.059(-0.096,-0.022)^{*}$ & $-0.041(-0.093,0.012)$ & $-0.037(-0.075,0.001)$ & $-0.115(-0.179,-0.050)^{*}$ & $-0.811(-1.081,-0.541)^{*}$ \\
\hline $\begin{array}{l}\text { PASE score tertiles: } \\
\text { Lower } \\
\text { Mid } \\
\text { Upper }\end{array}$ & $\begin{array}{c}\text { Reference } \\
0.809(0.419,1.200)^{*} \\
0.592(0.176,1.008)^{*}\end{array}$ & $\begin{array}{c}\text { Reference } \\
1.358(0.796,1.919)^{*} \\
1.166(0.569,1.764)^{*}\end{array}$ & $\begin{array}{c}\text { Reference } \\
1.283(0.882,1.685)^{*} \\
1.096(0.669,1.524)^{*}\end{array}$ & $\begin{array}{c}\text { Reference } \\
1.836(1.148,2.523)^{*} \\
1.381(0.649,2.113)^{*}\end{array}$ & $\begin{array}{c}\text { Reference } \\
5.148(2.244,8.052)^{*} \\
7.072(3.972,10.17)^{*}\end{array}$ \\
\hline $\begin{array}{l}\text { PPT total tertiles: } \\
\text { Lower } \\
\text { Mid } \\
\text { Upper }\end{array}$ & $\begin{array}{c}\text { Reference } \\
1.155(0.783,1.526)^{*} \\
1.285(0.909,1.661)^{*}\end{array}$ & $\begin{array}{c}\text { Reference } \\
0.899(0.363,1.434)^{*} \\
1.089(0.547,1.632)^{*}\end{array}$ & $\begin{array}{c}\text { Reference } \\
1.243(0.860,1.625)^{*} \\
1.409(1.021,1.796)^{*}\end{array}$ & $\begin{array}{c}\text { Reference } \\
3.035(2.396,3.673)^{*} \\
4.553(3.907,5.199)^{*}\end{array}$ & $\begin{array}{c}\text { Reference } \\
6.433(3.677,9.188)^{*} \\
7.302(4.514,10.09)^{*}\end{array}$ \\
\hline $\begin{array}{l}\text { Current smoker } \\
\text { No } \\
\text { Yes }\end{array}$ & $\begin{array}{c}\text { Reference } \\
-0.735(-1.112,-0.359) *\end{array}$ & $\begin{array}{c}\text { Reference } \\
-1.151(-1.687,-0.615)^{*}\end{array}$ & $\begin{array}{c}\text { Reference } \\
-1.190(-1.575,-0.805) *\end{array}$ & $\begin{array}{c}\text { Reference } \\
-2.502(-3.158,-1.847) *\end{array}$ & $\begin{array}{c}\text { Reference } \\
-10.95(-13.69,-8.207)^{*}\end{array}$ \\
\hline $\begin{array}{l}\text { Alcohol ( } \geq 1 \text { day/week) } \\
\text { No } \\
\text { Yes }\end{array}$ & $\begin{array}{c}\text { Reference } \\
0.257(-0.047,0.562)\end{array}$ & $\begin{array}{c}\text { Reference } \\
0.180(-0.255,0.615)\end{array}$ & $\begin{array}{c}\text { Reference } \\
1.014(0.704,1.324)^{*}\end{array}$ & $\begin{array}{c}\text { Reference } \\
2.159(1.630,2.687)^{*}\end{array}$ & $\begin{array}{c}\text { Reference } \\
8.521(6.307,10.74)^{*}\end{array}$ \\
\hline
\end{tabular}


Table 3. Association between cognitive test scores and serum 25(OH)D levels: linear regression analyses

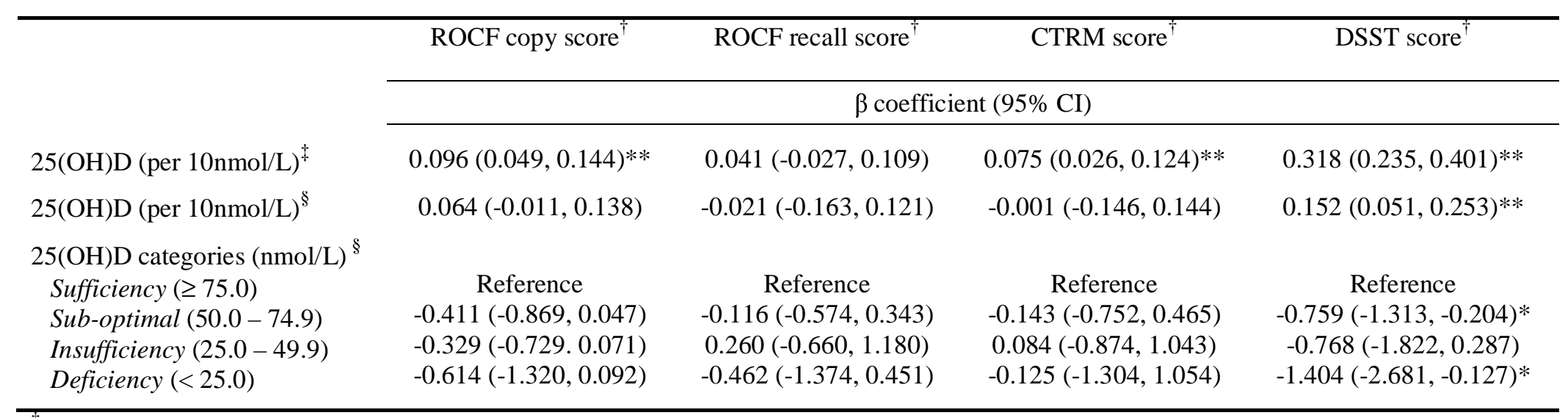

\footnotetext{
${ }^{\dagger}$ Dependent variables

Adjusted for age

${ }^{\S}$ Adjusted for age, education, depression, body mass index, physical activity, physical performance, smoking, alcohol consumption, centre and season $* P<0.05, * * P<0.01$

ROCF $=$ Rey-Osterrieth Complex Figure, CTRM = Camden Topographical Recognition Memory, DSST = Digit Symbol Substitution Test
} 
Table 4. Association between cognitive test scores and serum $25(\mathrm{OH}) \mathrm{D}$ levels: spline regression analyses

\begin{tabular}{|c|c|c|c|c|}
\hline & ROCF copy score ${ }^{\dagger}$ & $\mathrm{ROCF}$ recall score ${ }^{\dagger}$ & CTRM score $^{\dagger}$ & DSST score $^{\dagger}$ \\
\hline & \multicolumn{4}{|c|}{$\beta$ coefficient $(95 \% \mathrm{CI})-$ per $10 \mathrm{nmol} / \mathrm{L} 25(\mathrm{OH}) \mathrm{D}$} \\
\hline $\begin{array}{l}\text { Spline model } 1^{\ddagger} \\
25(\mathrm{OH}) \mathrm{D} \leq 35 \mathrm{nmol} / \mathrm{L} \\
25(\mathrm{OH}) \mathrm{D} \geq 35 \mathrm{nmol} / \mathrm{L}\end{array}$ & $\begin{array}{c}0.556(0.207,0.906)^{* *} \\
0.059(0.004,0.114)^{*}\end{array}$ & $\begin{array}{c}0.693(0.192,1.194)^{* *} \\
-0.011(-0.090,0.068)\end{array}$ & $\begin{array}{c}0.588(0.228,0.948)^{* *} \\
0.034(-0.023,0.091)\end{array}$ & $\begin{array}{l}1.171(0.562,1.780) * * * \\
0.250(0.154,0.346) * * *\end{array}$ \\
\hline $\begin{array}{l}\text { Spline model } 2^{\S} \\
25(\mathrm{OH}) \mathrm{D} \leq 35 \mathrm{nmol} / \mathrm{L} \\
25(\mathrm{OH}) \mathrm{D} \geq 35 \mathrm{nmol} / \mathrm{L}\end{array}$ & $\begin{array}{l}0.192(-0.349,0.733) \\
0.054(-0.030,0.138)\end{array}$ & $\begin{array}{c}0.323(-0.023,0.669) \\
-0.046(-0.201,0.109)\end{array}$ & $\begin{array}{c}0.150(-0.229,0.530) \\
-0.012(-0.172,0.148)\end{array}$ & $\begin{array}{l}0.398(-0.451,1.247) \\
0.134(-0.001,0.275)\end{array}$ \\
\hline
\end{tabular}

Dependent variables

${ }^{\ddagger}$ Adjusted for age

${ }^{\S}$ Adjusted for age, education, depression, body mass index, physical activity, physical performance, smoking, alcohol consumption, centre and season

$* P<0.05, * * P<0.01, * * * P<0.001$ 
Figure 1.

A

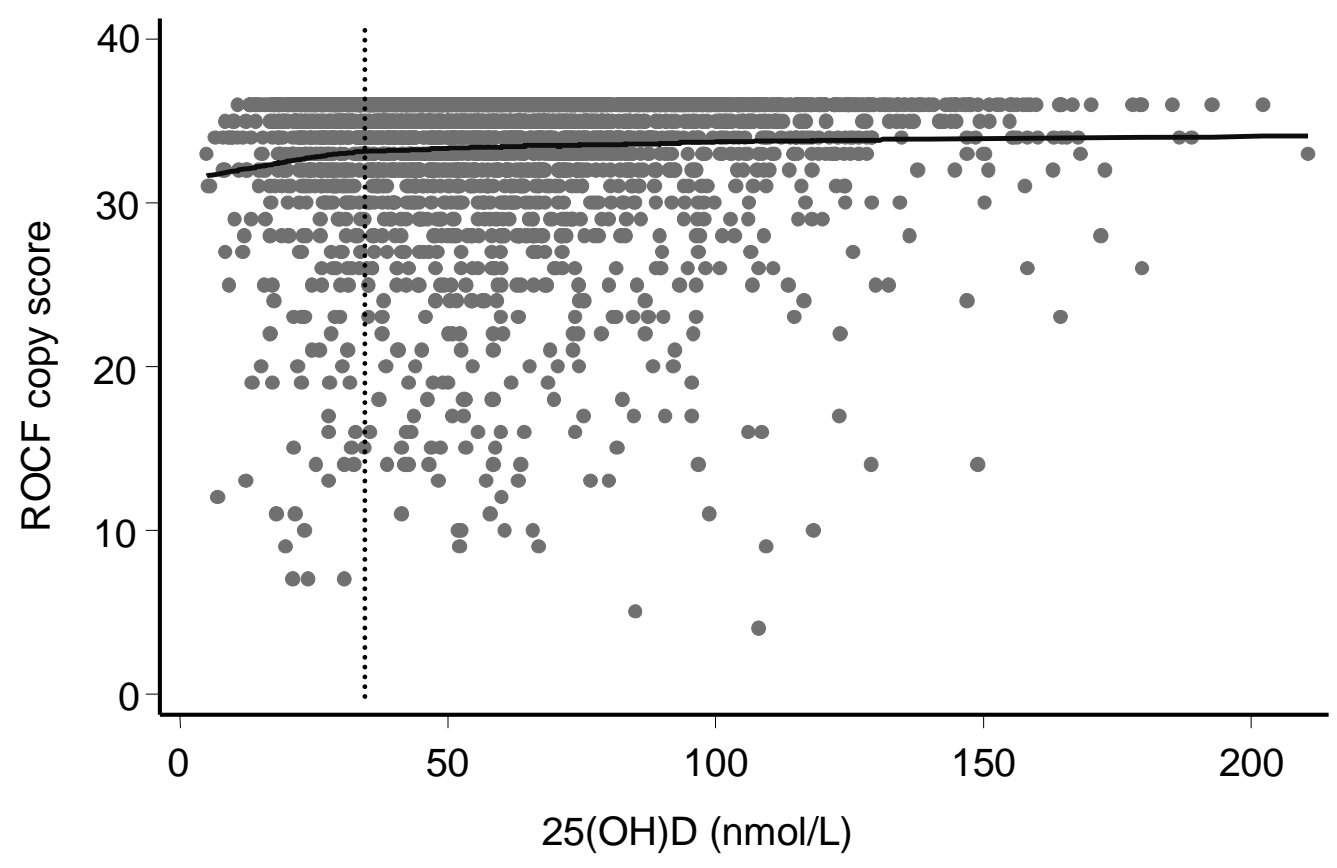

B

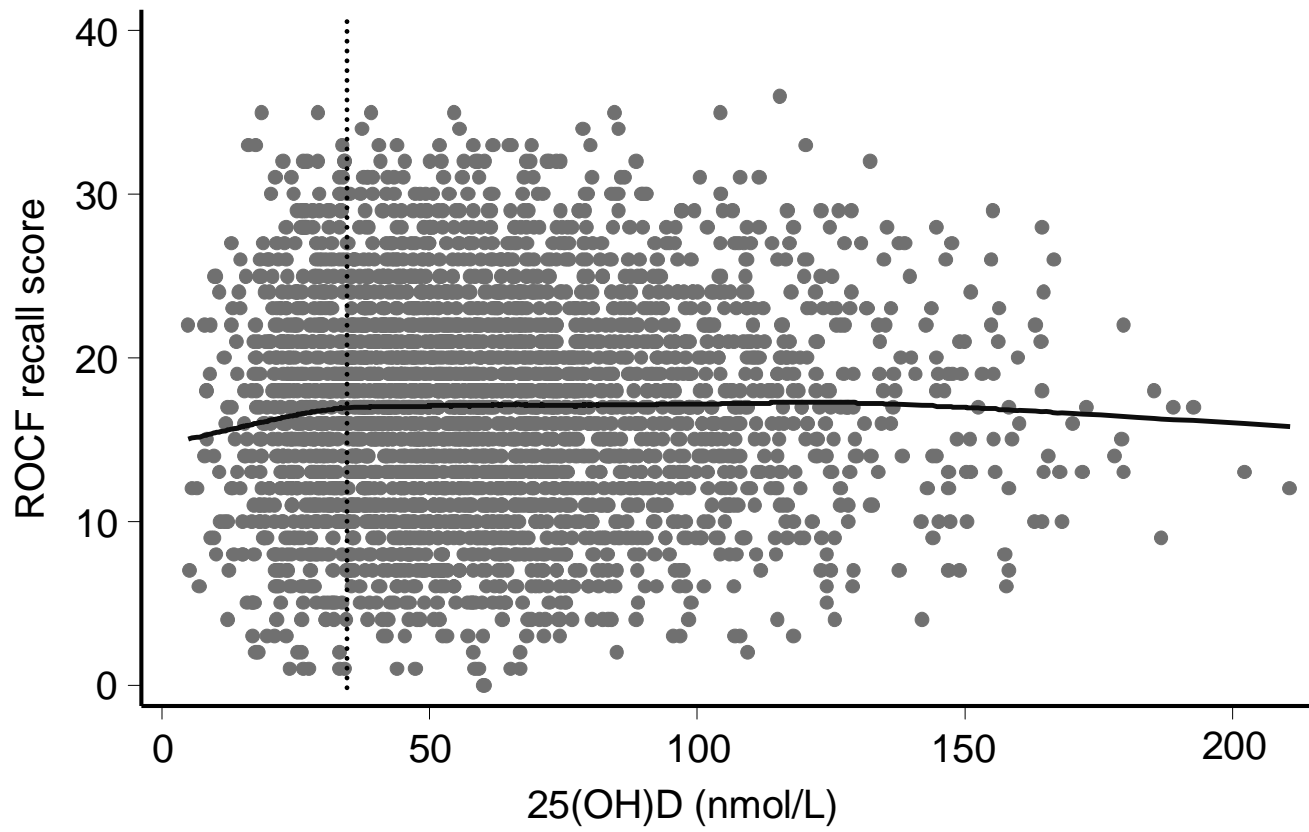


C

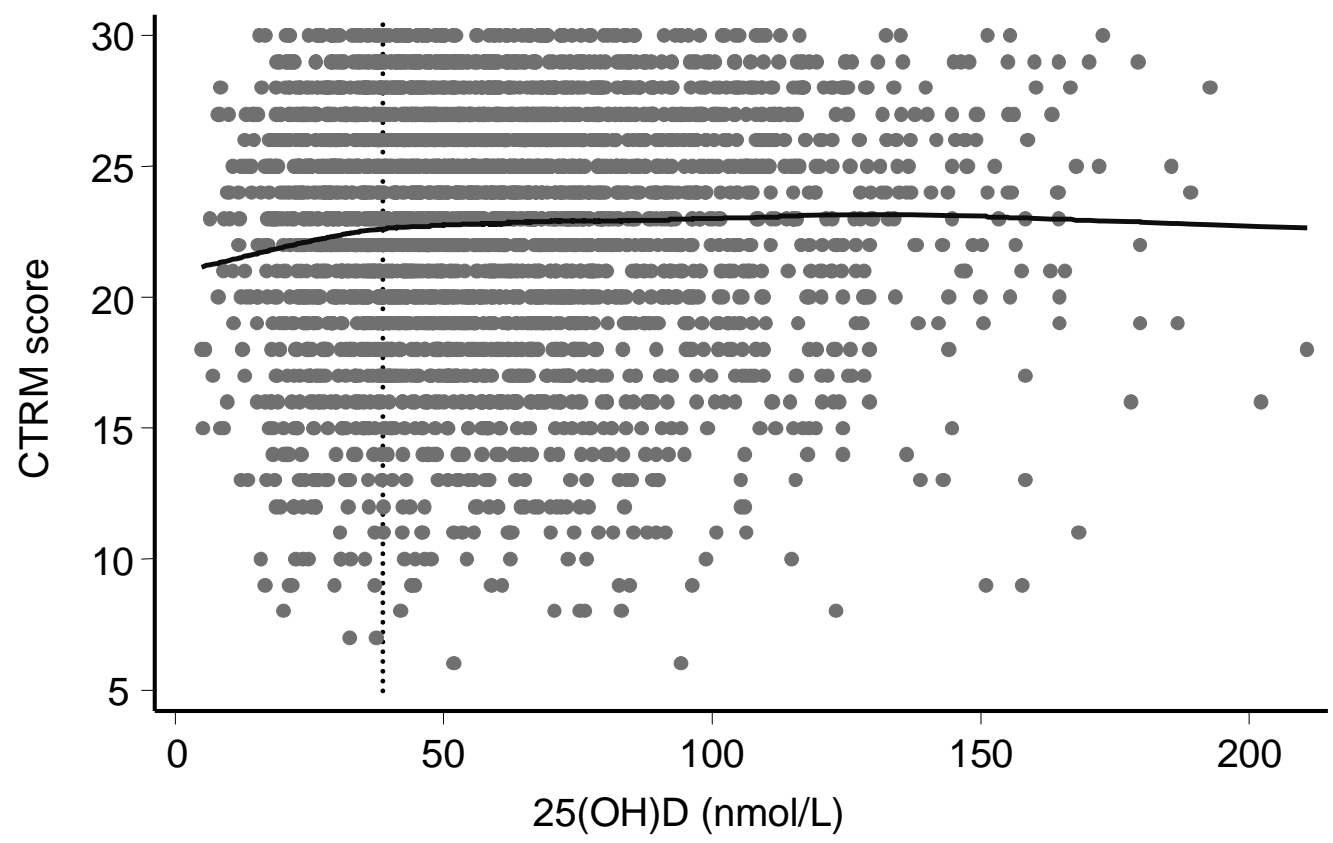

D

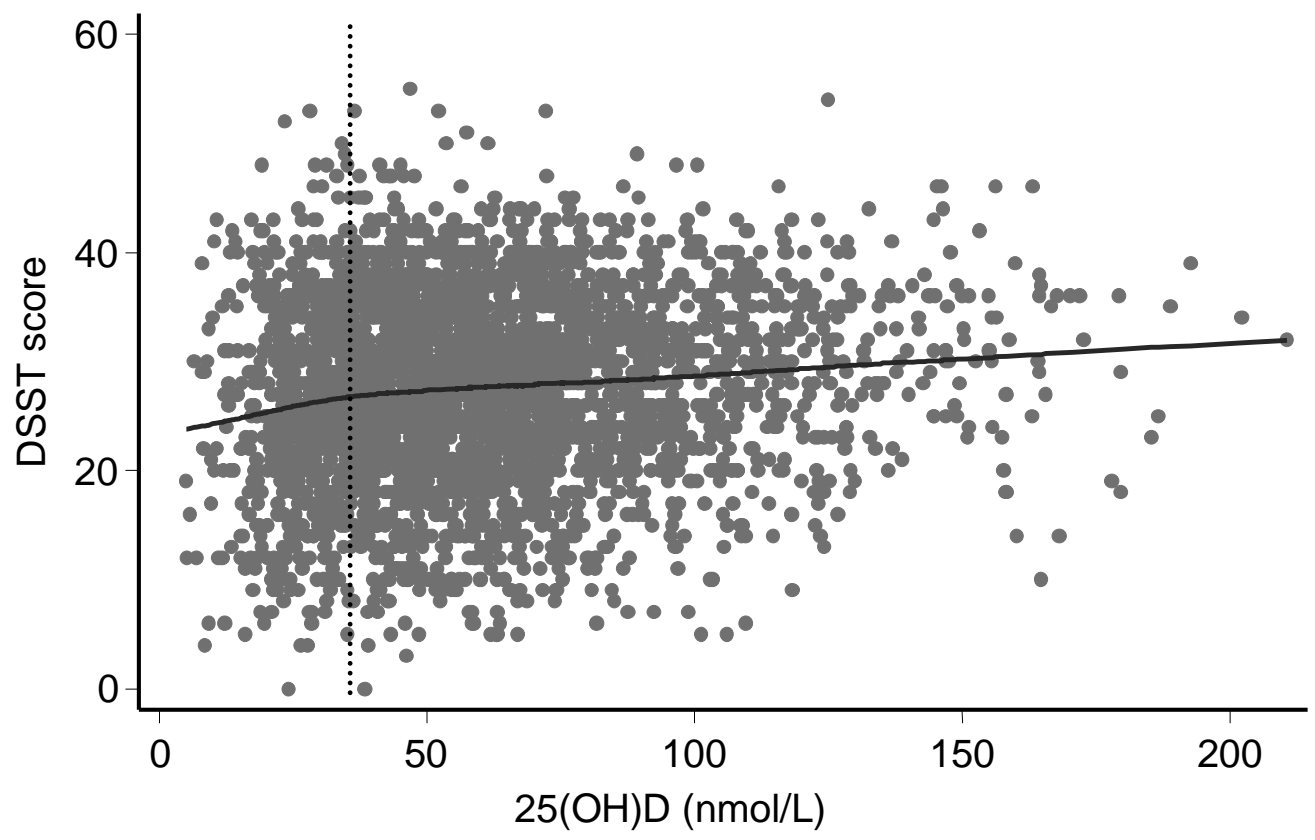

— LOWESS fit - Scatter 


\section{FIGURE LEGEND}

Figure 1. Relationship between $25(\mathrm{OH}) \mathrm{D}$ and cognitive function: LOWESS plots adjusted for age $(\mathrm{A}=$ Rey-Osterrieth Complex Figure copy, $\mathrm{B}=$ Rey-Osterrieth Complex Figure recall, $\mathrm{C}=$ Camden Topographical Recognition Memory, D = Digit-Symbol Substitution). The vertical dotted line represents the estimated $25(\mathrm{OH}) \mathrm{D}$ level at which the slope of the vitamin D - cognition relationship changes. 
1. Lips P. Vitamin D deficiency and secondary hyperparathyroidism in the elderly: consequences for bone loss and fractures and therapeutic implications. Endocr.Rev. 2001;22:477-501.

2. Holick MF. Evolution and function of vitamin D. Recent Results Cancer Res. 2003;164:3-28.

3. McCann JC, Ames BN. Is there convincing biological or behavioral evidence linking vitamin D deficiency to brain dysfunction? FASEB J. 2008;22:982-1001.

4. Kalueff AV, Tuohimaa P. Neurosteroid hormone vitamin D and its utility in clinical nutrition. Curr.Opin.Clin.Nutr.Metab Care 2007;10:12-9.

5. Zittermann A. Vitamin D in preventive medicine: are we ignoring the evidence? Br.J.Nutr. 2003;89:552-72.

6. Jones G, Strugnell SA, DeLuca HF. Current understanding of the molecular actions of vitamin D. Physiol Rev. 1998;78:1193-231.

7. Eyles DW, Smith S, Kinobe R, Hewison M, McGrath JJ. Distribution of the vitamin D receptor and 1 alpha-hydroxylase in human brain. J.Chem.Neuroanat. 2005;29:21-30.

8. Kalueff AV, Minasyan A, Keisala T, Kuuslahti M, Miettinen S, Tuohimaa P. The vitamin D neuroendocrine system as a target for novel neurotropic drugs. CNS.Neurol.Disord.Drug Targets. 2006;5:363-71. 
9. Brewer LD, Thibault V, Chen KC, Langub MC, Landfield PW, Porter NM. Vitamin D hormone confers neuroprotection in parallel with downregulation of L-type calcium channel expression in hippocampal neurons. J.Neurosci. 2001;21:98-108.

10. Brewer LD, Porter NM, Kerr DS, Landfield PW, Thibault O. Chronic 1alpha,25-(OH)2 vitamin D3 treatment reduces Ca2+-mediated hippocampal biomarkers of aging. Cell Calcium 2006;40:277-86.

11. Wilkins CH, Sheline YI, Roe CM, Birge SJ, Morris JC. Vitamin D deficiency is associated with low mood and worse cognitive performance in older adults. Am.J.Geriatr.Psychiatry 2006;14:1032-40.

12. Oudshoorn C, Mattace-Raso FU, van d, V, Colin EM, van der Cammen TJ. Higher serum vitamin D3 levels are associated with better cognitive test performance in patients with Alzheimer's disease. Dement.Geriatr.Cogn Disord. 2008;25:539-43.

13. Przybelski RJ, Binkley NC. Is vitamin D important for preserving cognition? A positive correlation of serum 25-hydroxyvitamin D concentration with cognitive function. Arch.Biochem.Biophys. 2007;460:202-5.

14. McGrath J, Scragg R, Chant D, Eyles D, Burne T, Obradovic D. No association between serum 25-hydroxyvitamin D3 level and performance on psychometric tests in NHANES III. Neuroepidemiology 2007;29:49-54.

15. Lee DM, O'Neill TW, Pye SR, Silman AJ, Finn JD, Pendleton N, Tajar A, Bartfai G, Casanueva F, Forti G, Giwercman A, Huhtaniemi IT, Kula K, Punab M, Boonen S, Vanderschueren D, Wu FC. The European Male Ageing Study (EMAS): design, methods and recruitment. Int.J.Androl 2008. 
16. Washburn RA, Smith KW, Jette AM, Janney CA. The Physical Activity Scale for the Elderly (PASE): development and evaluation. J.Clin.Epidemiol. 1993;46:153-62.

17. Beck AT, Steer RA, Brown GK. Manual for the Beck Depression Inventory-II. San Antonio, TX: Psychological Corporation, 1996.

18. Reuben DB, Siu AL. An objective measure of physical function of elderly outpatients. The Physical Performance Test. J.Am.Geriatr.Soc. 1990;38:1105-12.

19. Osterrieth PA. Le test de copie d'une figure complexe. Arch Psychol 1944;30:206-356.

20. Warrington EK. The Camden memory tests manual. Hove: Psychology Press, 1996.

21. Uiterwijk JM. WAIS-III-NL/V. Lisse: Swets \& Zeitlinger, 2001.

22. Lips $\mathrm{P}$. Which circulating level of 25 -hydroxyvitamin D is appropriate? J.Steroid Biochem.Mol.Biol. 2004;89-90:611-4.

23. Holick MF. Vitamin D deficiency. N.Engl.J.Med. 2007;357:266-81.

24. Cleveland WS. Robust Locally Weighted Fitting and Smoothing Scatterplots. Journal of the American Statistical Association 1979;74:829-36.

25. Lumley T, Diehr P, Emerson S, Chen L. The importance of the normality assumption in large public health data sets. Annu.Rev.Public Health 2002;23:151-69.

26. Sonnenberg J, Luine VN, Krey LC, Christakos S. 1,25-Dihydroxyvitamin D3 treatment results in increased choline acetyltransferase activity in specific brain nuclei. Endocrinology 1986;118:1433-9. 
27. Wang Y, Chiang YH, Su TP, Hayashi T, Morales M, Hoffer BJ, Lin SZ. Vitamin D(3) attenuates cortical infarction induced by middle cerebral arterial ligation in rats. Neuropharmacology 2000;39:873-80.

28. Jorde R, Waterloo K, Saleh F, Haug E, Svartberg J. Neuropsychological function in relation to serum parathyroid hormone and serum 25-hydroxyvitamin D levels. The Tromso study. J.Neurol. 2006;253:464-70.

29. Holick MF. Vitamin D: importance in the prevention of cancers, type 1 diabetes, heart disease, and osteoporosis. Am.J.Clin.Nutr. 2004;79:362-71.

30. Grant WB. The likely role of vitamin D from solar ultraviolet-B irradiance in increasing cancer survival. Anticancer Res. 2006;26:2605-14.

31. Visser M, Deeg DJ, Lips P. Low vitamin D and high parathyroid hormone levels as determinants of loss of muscle strength and muscle mass (sarcopenia): the Longitudinal Aging Study Amsterdam. J.Clin.Endocrinol.Metab 2003;88:5766-72.

32. Scragg R, Sowers M, Bell C. Serum 25-hydroxyvitamin D, diabetes, and ethnicity in the Third National Health and Nutrition Examination Survey. Diabetes Care 2004;27:2813-8.

33. Breteler MM, Claus JJ, Grobbee DE, Hofman A. Cardiovascular disease and distribution of cognitive function in elderly people: the Rotterdam Study. BMJ 1994;308:1604-8.

34. Muller M, Grobbee DE, Aleman A, Bots M, van der Schouw YT. Cardiovascular disease and cognitive performance in middle-aged and elderly men. Atherosclerosis 2007;190:143-9. 
35. Verhaegen P, Borchelt M, Smith J. Relation between cardiovascular and metabolic disease and cognition in very old age: cross-sectional and longitudinal findings from the berlin aging study. Health Psychol. 2003;22:559-69.

36. Houston DK, Cesari M, Ferrucci L, Cherubini A, Maggio D, Bartali B, Johnson MA, Schwartz GG, Kritchevsky SB. Association between vitamin D status and physical performance: the InCHIANTI study. J.Gerontol.A Biol.Sci.Med.Sci. 2007;62:440-6.

37. Scharla SH. Prevalence of subclinical vitamin D deficiency in different European countries. Osteoporos.Int. 1998;8 Suppl 2:S7-12.

38. Bischoff-Ferrari HA. The 25-hydroxyvitamin D threshold for better health. J.Steroid Biochem.Mol.Biol. 2007;103:614-9.

39. Heaney RP. The case for improving vitamin D status. J.Steroid Biochem.Mol.Biol. 2007;103:635-41.

40. van der Wielen RP, Lowik MR, van den BH, de Groot LC, Haller J, Moreiras O, van Staveren WA. Serum vitamin D concentrations among elderly people in Europe. Lancet 1995;346:207-10.

41. Holick MF. High prevalence of vitamin D inadequacy and implications for health. Mayo Clin.Proc. 2006;81:353-73.

42. Trang HM, Cole DE, Rubin LA, Pierratos A, Siu S, Vieth R. Evidence that vitamin D3 increases serum 25-hydroxyvitamin D more efficiently than does vitamin D2. Am.J.Clin.Nutr. 1998;68:854-8.

43. Holick MF, Biancuzzo RM, Chen TC, Klein EK, Young A, Bibuld D, Reitz R, Salameh W, Ameri A, Tannenbaum AD. Vitamin D2 is as effective as vitamin D3 in maintaining 
circulating concentrations of 25-hydroxyvitamin D. J.Clin.Endocrinol.Metab 2008;93:677-81.

44. Armas LA, Hollis BW, Heaney RP. Vitamin D2 is much less effective than vitamin D3 in humans. J.Clin.Endocrinol.Metab 2004;89:5387-91. 